\title{
Advances in Silver Ion Chromatography for the Analysis of Fatty Acids and Triacylglycerols-2001 to 2011
}

\author{
Svetlana M. MomchiLova ${ }^{\dagger}$ and Boryana M. Nikolova-Damyanova \\ Department of Lipid Chemistry, Institute of Organic Chemistry with Centre of Phytochemistry, \\ Bulgarian Academy of Sciences, Acad. George Bonchev Str., bl. 9, Sofia 1113, Bulgaria
}

\begin{abstract}
An effort is made to critically present the achievements in silver ion chromatography during the last decade. Novelties in columns, mobile-phase compositions and detectors are described. Recent applications of silver ion chromatography in the analysis of fatty acids and triacylglycerols are presented while stressing novel analytical strategies or new objects. The tendencies in the application of the method in complementary ways with reversed-phase chromatography, chiral chromatography and, especially, mass detection are outlined.
\end{abstract}

(Received March 17, 2012; Accepted July 24, 2012; Published September 10, 2012)

1 Introduction

2 State-of-the-art

$2 \cdot 1$ Thin-layer chromatography

$2 \cdot 2$ Solid-phase extraction

$2 \cdot 3$ High-performance liquid chromatography

3 Application to Fatty Acids

$3 \cdot 1$ Separation of fatty acids according to the number of double bonds

3.2 Separation of cis/trans isomers

3.3 Separation of positionally isomeric fatty acids

$3 \cdot 4$ Separation of CLA
4 Application to Triacylglycerols

$4 \cdot 1$ Separation according to the number of double bonds

4.2 Separation of TAG differing in the position or/and configuration of double bonds in the acyl chains

4.3 Separation of regioisomeric TAG

5 Conclusions

6 Acknowledgements

7 References
841

\section{Introduction}

The introduction of silver ion chromatography was undoubtedly one of the major inventions made in lipid analysis in the middle of the 20th century. For the first time it was possible to separate natural and modified fatty acid (FA) and triacylglycerol (TAG) mixtures into simpler fractions differing by a single property of the molecule, the number and configuration of double bonds. The principle of silver ion complexation with double bonds, well known in organic chemistry, was successfully employed along with the already existing chromatographic techniques, thin-layer chromatography (TLC) and atmospheric pressure column chromatography, giving new promising information on

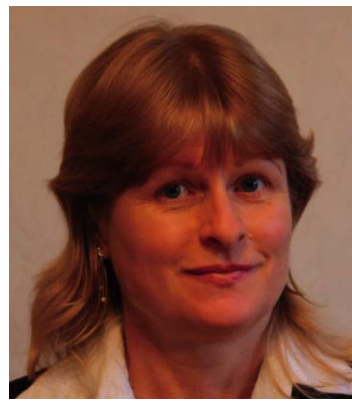

Svetlana MomchiLova obtained her $\mathrm{PhD}$ in 2002 from the Institute of Organic Chemistry with Centre of Phytochemistry, Bulgarian Academy of Sciences (IOCCPBAS), studying the mechanism for the separation of isomeric fatty acids by silver-ion chromatography. As a Postdoc Fellow (2002 - 2004) of JSPS in Hokkaido University, Hakodate, she investigated the mechanism for the separation of regioisomeric triacylglycerols by reversed-phase chromatography as well. Since 2007 she has been an Associate Professor at the IOCCP-BAS, and since 2010, Head of the Laboratory of Lipid Chemistry. Her scientific work includes chromatographic methods for the identification, separation and quantification of lipids, and, especially, the analysis of isomeric fatty acids and triacylglycerols.

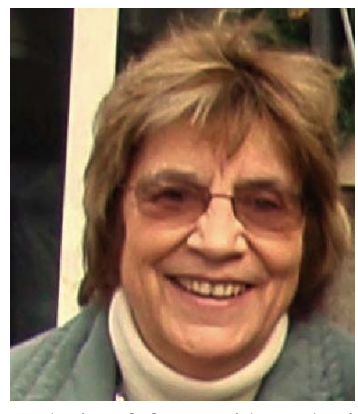

Boryana NiKolova-Damyanova obtained her $\mathrm{PhD}$ in analytical chemistry in 1981 after joining (1973) the Laboratory of Lipid Chemistry at the Institute of Organic Chemistry with Centre of Phytochemistry, Bulgarian Academy of Sciences (IOCCP-BAS). She was later appointed Head of the Chromatographic and Mass Spectral Laboratory (1993) at IOCCP-BAS. Her research has focused mainly on mechanistic studies aiming to improve the methodology and application of silver-ion chromatography in the analysis of fatty acids and triacylglycerols in different matrices. Upon retirement, she became a consultant concerning analytical chemistry at the Joint Genomic Centre, a laboratory for contract analysis at the University of Sofia.

$\dagger$ To whom correspondence should be addressed.

E-mail: svetlana@orgchm.bas.bg 
the structure of natural FA and TAG. Starting from the 1970-ies after solving a variety of technical problems, silver ion chromatography was adopted in high-performance liquid chromatography (Ag-HPLC), supercritical fluid chromatography (Ag-SFC) and solid-phase extraction (Ag-SPE). The early stages of silver ion chromatography were summarized in the excellent review by Morris ${ }^{1}$ and after a long gap, in a series of books entitled Advances in Lipid Methodology $y^{2,3}$ and in the recent edition of the major Lipid Analysis book by Christie and Han. ${ }^{4}$ Many other reviews deserving attention are cited when appropriate in the text.

Since we trust that silver ion chromatography is still of major importance for lipid analysis, a modest attempt is made here to present the development (if any) in silver ion chromatography of FA and TAG during the last decade (2001 - 2011) concerning both new solutions in the techniques and chromatographic results. We are fully aware that the choice of papers to be presented and discussed as achievements is undoubtedly affected and limited by our personal interests and opinion.

\section{State-of-the-art}

\subsection{Thin-layer chromatography}

In the past, silver ion thin-layer chromatography (Ag-TLC) was the primary technique for lipid analysis. Important information on the composition of numerous natural fats and oils was obtained by means of this technique. The first attempts to understand the interactions occurring during the chromatographic process were made using Ag-TLC. Concerning the intensive use and studies during these early years, we are indebted to facts that later appeared to be valid for all chromatographic techniques using $\operatorname{Ag}(\mathrm{I})$ in either the stationary or mobile phase. The general elution order of fatty acids and triacylglycerols determined by the number of double bonds, the effects of the double-bond configuration and the position in the fatty acids carbon chain and the effects of the fatty acid moieties position in the glycerol backbone were formulated firstly by Ag-TLC. This technique is now rarely used mostly in a preparative mode prior to the gas chromatographic (GC) determination of isomeric (cis/trans mostly) fatty acids (see for example a paper of Kairenius et al.), ${ }^{5}$ and for the fractionation of highly unsaturated triacylglycerols, ${ }^{6}$ while no novelties in the technique have been reported. For more details about the application of Ag-TLC, some recent reviews are recommended where all aspects of the method are discussed., ${ }^{4-10}$

\subsection{Solid-phase extraction}

Solid-phase extraction (SPE) cartridges with a cation-exchange filling loaded with silver ions (Ag-SPE) have been successfully used instead of Ag-TLC for preliminary fractionation of FA mixtures. The approach was introduced by Christie; ${ }^{11}$ the procedure is easy to perform, and produces clean fractions of saturated, trans- and cis-monounsaturated fatty acids. It is occasionally used now prior to the GC analysis of isomeric FA in complex lipid samples. ${ }^{12-14}$

\subsection{High-performance liquid chromatography 2.3.1 Columns}

The efforts made to develop a stable silver loaded column providing reproducible separations have been well documented throughout the years. ${ }^{15,16}$ A breakthrough was made by Christie, who described a procedure for a laboratory-made silver ion column using a commercial cation-exchange column. ${ }^{17}$ Based on the same, or close, procedure, a commercial ChromSpher
Lipids $^{\mathrm{TM}}$ (CSL) column by Varian-Chrompack International (Middelburg, Netherlands) appeared later and is presently dominating in Ag-HPLC. Because of unclear and not openly commented limitations in mobile-phase compositions for use with CSL columns, efficient resolution of complex FA, like conjugated linoleic acids (CLA), ${ }^{18}$ and TAG mixtures, like TAG containing $\mathrm{CLA}^{19}$ or positionally isomeric $\mathrm{TAG},{ }^{20}$ was achieved by connecting of two to six CSL columns in series.

Very recently, a new material has been suggested as a suitable stationary phase to perform "argentation" chromatography. ${ }^{21,22}$ It involves the well-known and widely spread use of silica gel functionalized with thiol groups to cleaning water from the ions of some heavy metals, $\operatorname{Ag}(\mathrm{I})$ among these. The property of thiol groups to form stable covalent complexes with $\mathrm{Ag}(\mathrm{I})$ is exploited to produce a silica-gel based material as a stationary phase in column chromatography (conventional and high performance column chromatography) for the separation of triacylglycerols (among other unsaturated organic compounds). It is supposed that this material, denoted as AgTCM (silver thiolate chromatographic material), is highly stable, reusable for a substantially longer time than the conventional stationary phases loaded with silver ions (commercial and laboratory-made), and that there is practically no leaking of silver from the column, which is by all means useful for the liquid chromatographymass-spectrometry (LC-MS) of lipids. At this stage it is too early to say whether the new material will find broad applications in lipid analysis, but the idea deserves attention.

As shown previously, ${ }^{23}$ the "disappearance" of the much cheaper, stable and reproducible laboratory loaded column is supposed to be caused by changes occurring in manufacturing the commercial cation exchange columns. The lower carbon load on the stationary phase (probably accompanied by other physical and/or topological changes) resulted in inferior loading, and to an unstable, inefficient, poorly working column.

The attempts concerning the on-line connection of reversed phase (RP) and silver ions (Ag) columns, denoted as 2D LC, ${ }^{24-26}$ and supposed to technically simplify the off-line analysis, ${ }^{27}$ found limited application. At present, RP-HPLC and Ag-HPLC columns combined off-line and connected to a mass detector appear to be the most powerful tool in the analysis of complex TAG samples, as demonstrated by Holcapek and coworkers. ${ }^{28}$

\subsubsection{Mobile phases}

Hexane modified with a low amount $(<1.0 \%)$ of acetonitrile, introduced by Adlof and coworkers, ${ }^{29}$ has been the mobile phase used with CSL columns during the last decade, and few efforts have been made to test other solvent combinations. Since this mobile phase was found to give irreproducible retention times, the addition of $0.5 \%$ diethyl ether was found to ensure partial stabilizing, ${ }^{30}$ but complete elimination of any retention time shift $^{31}$ was not achieved. The addition of low amounts (up to $0.2 \%$ ) of 2-propanol to a hexane-acetonitrile mixture was shown (expectedly) to shorten the analysis of CLA methyl esters ${ }^{32}$ (CLA ME) and to improve (with reproducible retention times) the separation of positionally and geometrically isomeric 18:1 methyl esters (ME). ${ }^{33}$ Introducing 2-propanol was certainly a good idea, since this solvent allowed for varying the acetonitrile content in rather broad limits. As an alternative, 2\% acetic acid in hexane was used for the resolution of CLA ME, ${ }^{34}$ and $0.15 \%$ acetonitrile in 2-octane was found to be appropriate for the fractionation of trans and cis monoenoic ME. ${ }^{35}$ Propionitrile and butyronitrile were also tested as modifiers for both CLA ${ }^{36,37}$ and $\mathrm{TAG}^{38}$ separations. Heptane-acetonitrile and heptaneacetone were successfully applied to the separation of positionally isomeric TAG and TAG containing oleoyl- and elaidyl-moieties in partially hydrogenated vegetable oils. ${ }^{39}$ 


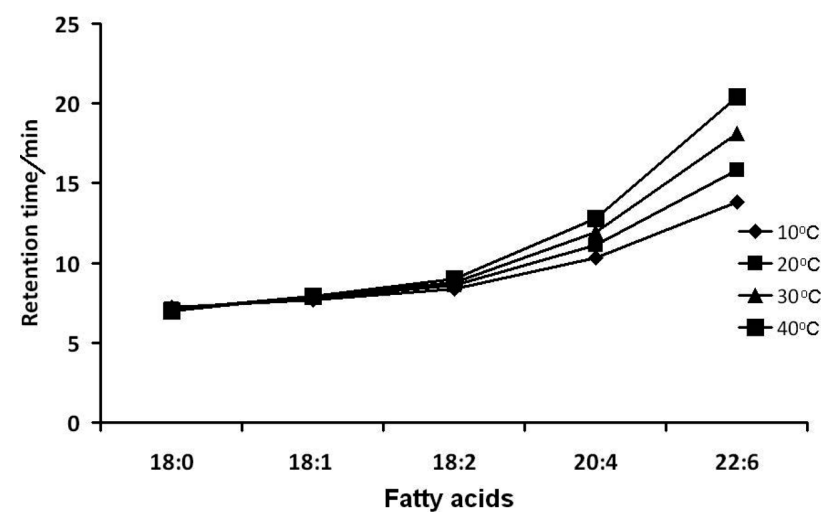

Fig. 1 Effect of temperature on the retention of fatty acid methyl esters. ${ }^{40}$ Two CSL columns connected in series, isocratic elution with $1.0 \%$ acetonitrile in hexane with a flow rate of $1.0 \mathrm{~mL} / \mathrm{min}$ : detection, $\mathrm{UV}$ at $206 \mathrm{~nm}$ and evaporative light scattering detector (ELSD); sample, mixture of methyl esters; sample size, $10 \mu \mathrm{g}$ (drawn by using the data in Table 3 of the original paper with permission of Elsevier).

Heptane-acetone phases were "too weak", however, to elute TAG with more than two double bonds in well shaped peaks.

The mobile phases based on chlorinated solvents modified with acetonitrile, methanol or 2-propanol, successfully previously employed in Ag-HPLC on columns loaded in laboratory with $\mathrm{Ag}^{+}$, were abandoned because of health reasons. However, their ability to easily combine with hexane, but also with numerous polar modifying solvents to give series of phases with fine tuned polarities affecting the resolution, remains unbeatable. The question that remains open is whether these solvents can be used with the CSL columns. It seems rather strange that there is no report as to where the resolution power of the two major types of mobile phases used so far in silver ion chromatography has been compared.

\subsubsection{Temperature}

Adlof ${ }^{40,41}$ was the first to notice that while many efforts were made to improve the resolution by looking for the most efficient mobile phase, little attention was paid to the effect of the temperature. The results clearly show that temperatures in the interval of $+40^{\circ} \mathrm{C}$ to $-20^{\circ} \mathrm{C}$ affects the retention, and that the effects depend on the structure of the analyte and, hence, might improve the resolution, as is evident from Figs. 1 and 2.

The interactions leading to these effects have not been clarified, and it is possible that the observed is a sum of the effects of the temperature on the analyte conformation and the solubility in the mobile phase, the solubility of acetonitrile in hexane, on the topology of the stationary phase and the behavior of the grafted chains. To the best of our knowledge, beside these two papers, ${ }^{40,41}$ no systematic examination on temperature effects in silver ion chromatography has been carried out so far.

\subsubsection{Detectors}

During the last decade, detection in HPLC was seriously advanced. Evaporative light-scattering detectors (ELSD) replaced the widely previously applied ultraviolet (UV) detector. The use of on-line mass spectrometric (MS) detection utilizing electrospray ionization (ESI) or atmospheric pressure chemical ionization (APCI) is constantly increasing. Details on the technique and many important applications are summarized elsewhere. ${ }^{4,42,43}$ The advantages of Ag-HPLC-APCI of TAG (on CSL columns) were unambiguously demonstrated in several interesting papers..$^{20,27,28,44}$ Recently, an atmospheric pressure photoionization mass detector (APPI-MS) was tested in the

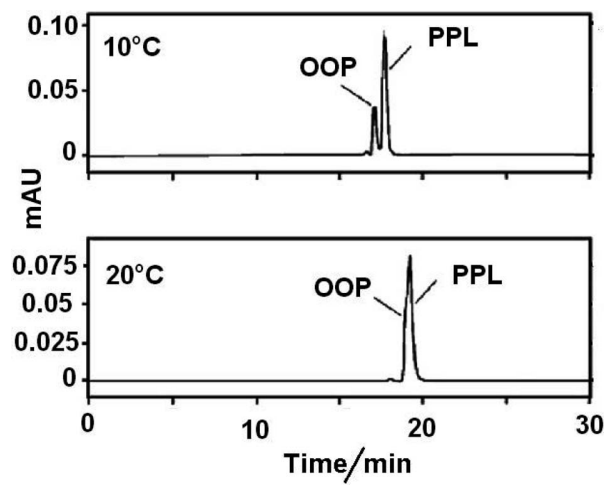

Fig. 2 Effect of temperature on the resolution of triacylglycerols: P, palmitic; O, oleic; L, linoleic acid moieties. ${ }^{41}$ Two CSL columns connected in series: mobile phase, $0.7 \%$ acetonitrile in hexane; a flow rate of $1.0 \mathrm{~mL} / \mathrm{min}$; ELSD; sample size, $10 \mu \mathrm{g}$ (redrawn from the original with permission of Elsevier).

analysis of $\mathrm{CLA}^{37}$ and isomeric octadecenoic methyl esters, ${ }^{33}$ and assumed to be a successful alternative to APCI. A significant increase in the signal-to-noise ratio $^{37}$ and extremely stable signals $^{33}$ were observed.

In continuous efforts to apply infrared detectors in HPLC, a CO laser-pumped dual-beam thermal lens (TLS) infrared spectrometer was tested for the direct detection of fatty acids. ${ }^{45}$ Compared to the UV detector, the TLS detector showed an inferior detection limit and sensitivity.

\section{Application to Fatty Acids}

\subsection{Separation of fatty acids according to the number of double bonds}

In the last decade, silver ion chromatography was rarely applied in FA analysis, mostly for the preparative isolation of FA isomers by using well-known procedures. Ag-SPE separation on silver impregnated Bond Elut SCX SPE columns prepared as reported by Christie ${ }^{11}$ (in 1989) was recently applied to fractionate saturated, monoenoic and dienoic FA in natural and partially hydrogenated soybean oils as methyl esters. ${ }^{46}$ Silica gel columns loaded with silver ions were used for the isolation of $\gamma$-linolenic acid (18:3 $\omega$-6) as methyl ester from microalgae lipids ${ }^{47}$ and stearidonic acid (18:4 $\omega$-3) as ethyl ester from modified soybean oil. ${ }^{48}$

Several studies ${ }^{49-51}$ employed silver ion TLC/densitometry for the separation and quantification of configurationally isomeric FA with 0 to 3 double bonds (as methyl or isopropyl esters). The procedure was applied for a rapid assessment of the authenticity of milk fats, ${ }^{49,51}$ margarines and frying fats (Fig. 3).$^{50}$

\subsection{Separation of cis/trans isomers}

Silver ion chromatography is most frequently applied for the preliminary fractionation of trans and cis isomeric FA prior to GC analysis to ensure correct separation, identification and quantification of all isomers. Most of the reported procedures (see recent reviews, Refs. 52 - 54) focus on trans octadecenoic (18:1) FA, but applications on polyunsaturated trans FA are also described. ${ }^{55}$ Ag-TLC and Ag-HPLC were found to be fully equivalent for this purpose. ${ }^{56}$ The quantitative Ag-TLC/ densitometry of isopropyl esters was successfully used to estimate the seasonal variation of trans FA in butter fats. ${ }^{57}$

Following a procedure by Christie, ${ }^{11} \mathrm{Ag}$-SPE was applied to 


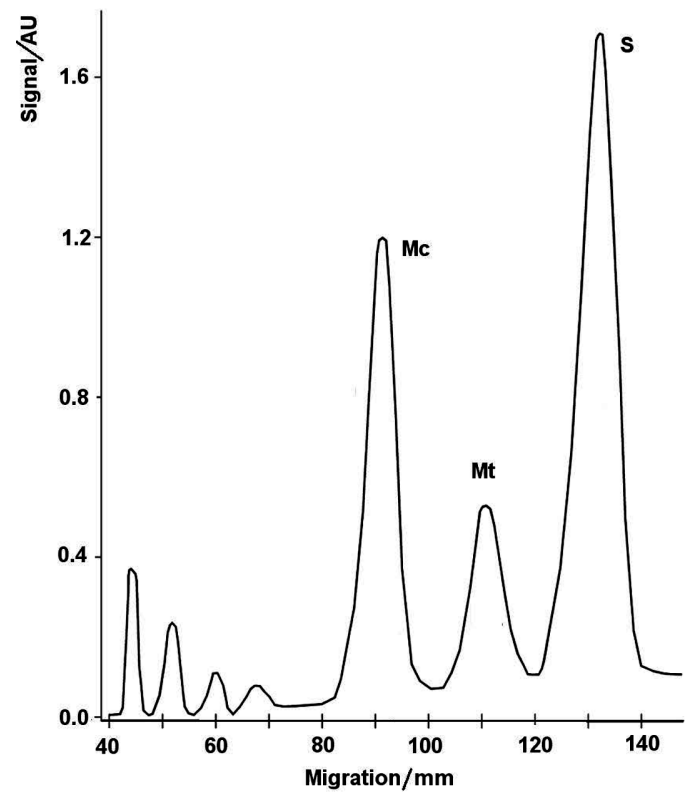

Fig. 3 Densitogram of cis/trans fatty acids (S, saturated; M, monoenoic; $\mathrm{c}$, cis; $\mathrm{t}$, trans) in a Bulgarian bovine butter sample separated by Ag-TLC. ${ }^{49}$ Plates were impregnated with $0.5 \% \mathrm{AgNO}_{3}$. Mobile phase: $3.5 \mathrm{~mL}$ petroleum ether:acetone, 100:2 (v/v) (redrawn from the original with permission of Akademiai Kiado).

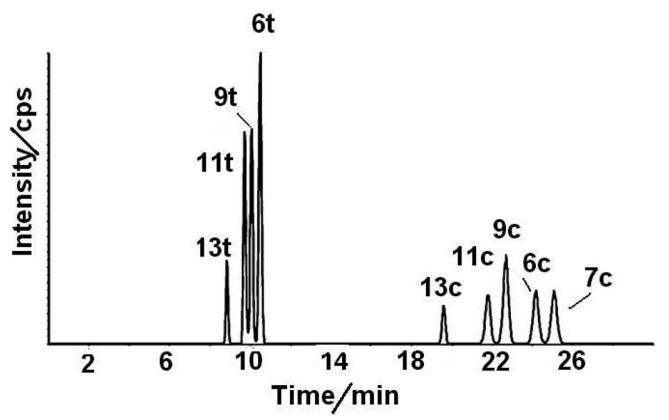

Fig. 4 Ag-HPLC-MS separation of C18:1 trans (t) and cis (c) positional isomers. ${ }^{33}$ Single CSL column; isocratic elution with $18 \%$ of hexane:2-propanol:acetonitrile, 100:1:0.1 (v/v/v) in hexane at a flow rate of $0.2 \mathrm{~mL} / \mathrm{min}$; sample size, $54 \mathrm{ng}$; detection by atmospheric pressure photoionization (APPI); extracted ion chromatogram $(\mathrm{m} / \mathrm{z}$ 297) (redrawn from the original with permission of Elsevier).

confirm the configuration of the rare cis 7-20:1 isomer (as methyl ester) in marine sediments. ${ }^{58}$ The preparative Ag-TLC of fatty acid methyl esters (FAME) was applied for isolating of the cis, cis 18:2 fraction in commercial bovine lipids, while attempting to check the authenticity of bovine milk. ${ }^{59}$ The fractionation of trans and cis 17:1 ME was achieved by Ag-HPLC on three CSL columns. ${ }^{35}$

\subsection{Separation of positionally isomeric fatty acids}

The application of Ag-HPLC in the analysis of positionally isomeric FA other than CLA has been reviewed in several papers and books. ${ }^{4,16,60,61}$ Recently, nine isomeric octadecenoic FAMEs were well-separated on a single CSL silver ion column using a mobile phase of hexane modified with acetonitrile and 2-propanol (Fig. 4). ${ }^{33}$

In a series of papers the authors of this review had shown that the derivatization of fatty acids with aromatic moieties, besides

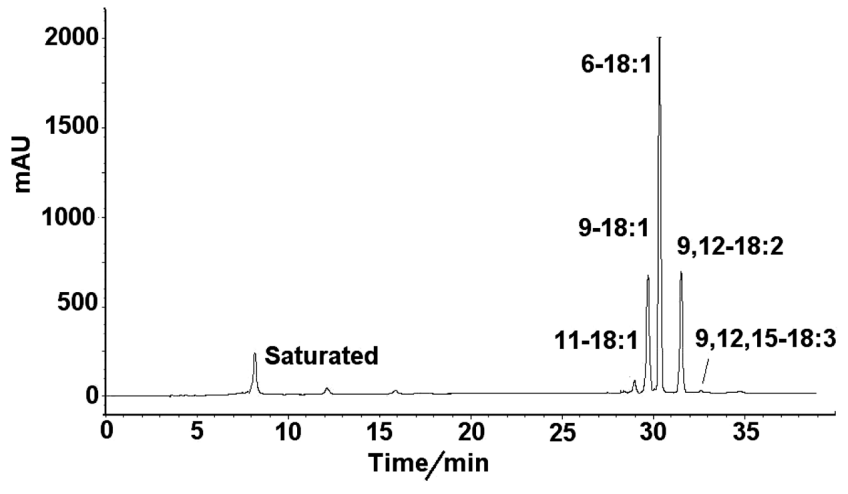

Fig. 5 Fatty acid composition of aniseed oil by Ag-HPLC with clear resolution of the three positional 6-, 9- and 11-18:1 isomers. ${ }^{63}$ Fatty acids were converted in $p$-methoxyphenacyl derivatives prior the analysis. Single Nucleosil ${ }^{\mathrm{TM}} 100-5 \mathrm{SA}$ column converted in silver ion form, stepwise gradient elution from 100\% dichloromethane to 99:1 dichloromethane:acetonitrile (v/v) over $30 \mathrm{~min}$ and to 97:3 dichloromethane:acetonitrile (v/v) over another $30 \mathrm{~min}$; sample size, $5 \mu \mathrm{g}$ (redrawn from the original with permission of AOAC International).

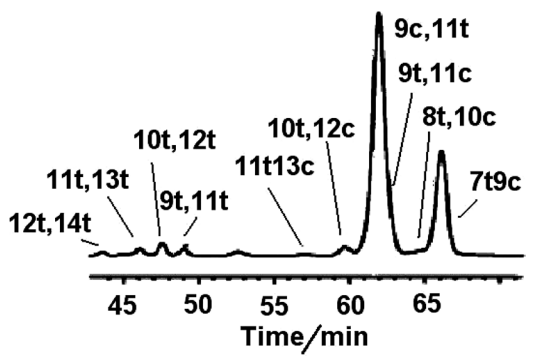

Fig. 6 CLA region (c, cis; $\mathrm{t}$, trans positional isomers) of a milk fat fatty acid methyl esters by Ag-HPLC. ${ }^{52}$ Three CSL columns connected in series; mobile phase of $0.1 \%$ acetonitrile and $0.5 \%$ diethyl ether in hexane with a flow rate of $1.0 \mathrm{~mL} / \mathrm{min}$; UV detection at $233 \mathrm{~nm}$ (redrawn from the original with permission of AOAC International).

increasing the detection limits in UV, resulted in a substantially increased resolution of positionally isomeric FA. Differentiating between cis and trans positional isomers was achieved in a single chromatographic run on a single silver-loaded Nucleosil ${ }^{\mathrm{TM}}$ 100-5SA column (results are summarized in Refs. 16, 61, 62). The protocol was recently applied to the simultaneous separation and quantification of FA, including the three naturally occurring positional 18:1 isomers, in Apiaceae seed oil (Fig. 5). ${ }^{63}$

\subsection{Separation of CLA}

The application of Ag-HPLC in FA analysis has mainly focused on CLA ME. There are no new elements in the procedures, three or four CSL columns connected in series, a mobile phase of $0.1 \%$ acetonitrile in hexane and UV detection at $230-233 \mathrm{~nm}$ are mostly in use (Fig. 6, achievements reviewed in Refs. 18, 31, 64-67). Recently, Ag-HPLC has been applied for the determination of CLA in commercial CLA-fortified dairy products, ${ }^{68}$ Portuguese CLA-rich food, ${ }^{69}$ Brazilian dairy products, ${ }^{70}$ a variety of UK foods, ${ }^{71}$ goat milk, ${ }^{72}$ ewe milk fat, ${ }^{73,74}$ beef lipids, ${ }^{75,76}$ bovine fat, ${ }^{77}$ bulls, ${ }^{78}$ human milk fat, ${ }^{79}$ Bifidobacterium and lactic acid bacteria. ${ }^{80}$ Novelties in the analytical procedures have not been reported. Similar chromatographic conditions (CSL column, mobile phase of $87 \%$ 


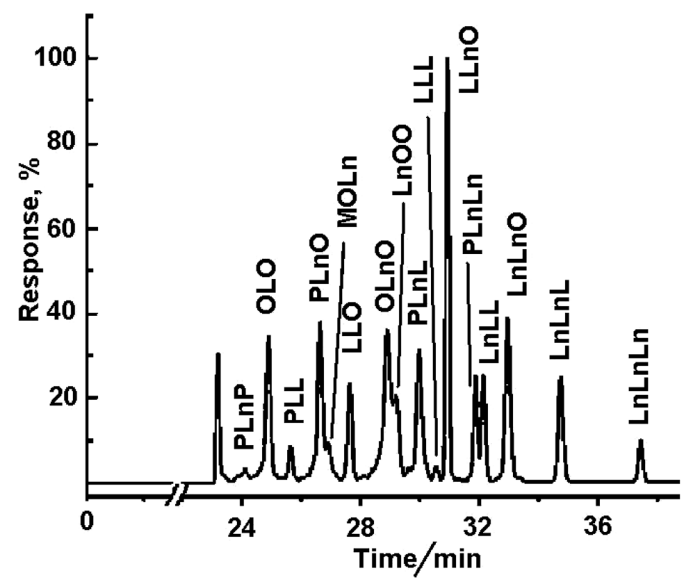

Fig. 7 Separation of triacylglycerols (M, myristic; P, palmitic; O, oleic; L, linoleic; Ln, linolenic acid moieties) in fat body in bumblebee by Ag-HPLC-APCI-MS. ${ }^{82}$ Single CSL column; stepwise gradient of hexane:2-propanol:acetonitrile, 30:9:1 (v/v/v) in hexane at a flow rate of $1 \mathrm{~mL} / \mathrm{min}$; sample size, $1 \mu \mathrm{g}$ (redrawn from the original with permission of Elsevier).

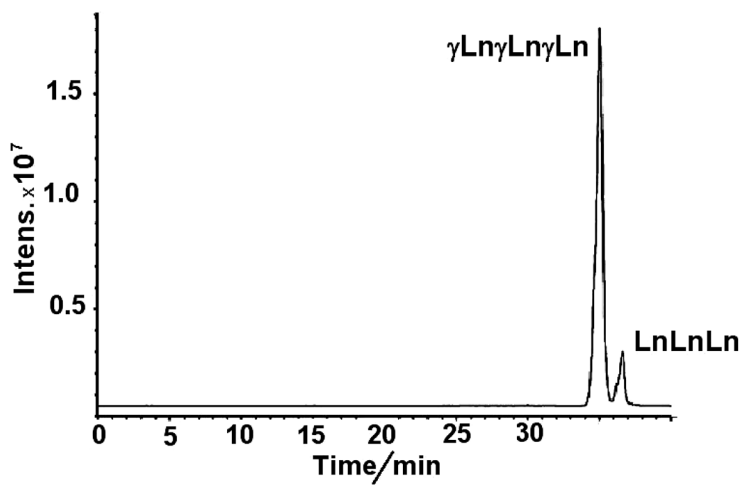

Fig. 8 Separation of triacylglycerols differing by the position of double bonds in the acyl chain ( $\gamma \mathrm{Ln}$ : 6,9,12-18:3 and $\mathrm{Ln}: 9,12,15-18: 3$ acyl moiety) by Ag-HPLC-APCI-MS. ${ }^{20}$ Three CSL columns connected in series with a gradient of $100 \%$ acetone to acetone:acetonitrile, 94:6 $(\mathrm{v} / \mathrm{v})$ and to acetone:acetonitrile 89:11 (v/v) over $75 \mathrm{~min}$ at a flow rate of $1 \mathrm{~mL} / \mathrm{min}$ (redrawn from the original with permission of Elsevier).

hexane and $13 \%$ hexane:acetonitrile, 100:2 (v/v) at $1 \mathrm{~mL} / \mathrm{min})$ were also used for the separation of two conjugated linolenic acid (CLnA) isomers. ${ }^{81}$

\section{Application to Triacylglycerols}

\section{4-1 Separation according to the number of double bonds}

Most of the achievements in this specific topic were reviewed elsewhere, for $\mathrm{Ag}-\mathrm{TLC}^{10}$ and for Ag-HPLC (see Fig. 7). ${ }^{23}$

Silver ion-super critical fluid chromatography is rarely, but steadily, used for this purpose (with capillary and conventional columns), and on-line MS detection is a novelty. ${ }^{83}$

\subsection{Separation of TAG differing in the position or/and configuration of double bonds in the acyl chains}

Most of the recent work has been aimed to test the CSL column with ELS and/or MS detectors in separations that were achieved previously on a silver-loaded cation exchange or silica

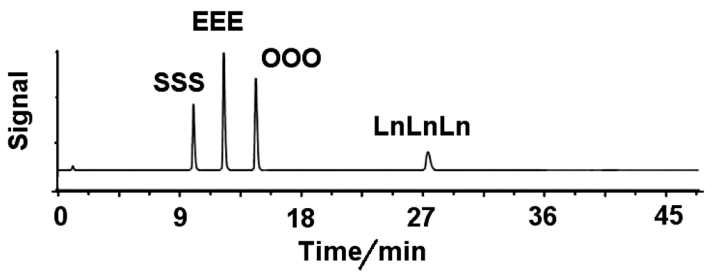

Fig. 9 Separation of a test mixture of triacylglycerols (S, 18:0; E, trans 9-18:1; O, cis 9-18:1; Ln, all cis 9,12,15-18:3 acyl residues) by Ag-HPLC using non-commercial AgTCM (silver thiolate chromatographic material) column $(150 \mathrm{~mm} \times 3 \mathrm{~mm}, 3 \mu \mathrm{m}$ particle size). ${ }^{22}$ Stepwise gradient from $100 \%$ hexane to $100 \%$ acetone over $45 \mathrm{~min}$ at a flow rate of $0.5 \mathrm{~mL} / \mathrm{min}$; sample size, 5 - $10 \mu \mathrm{g}$; ELSD (redrawn from the original with permission of Elsevier).

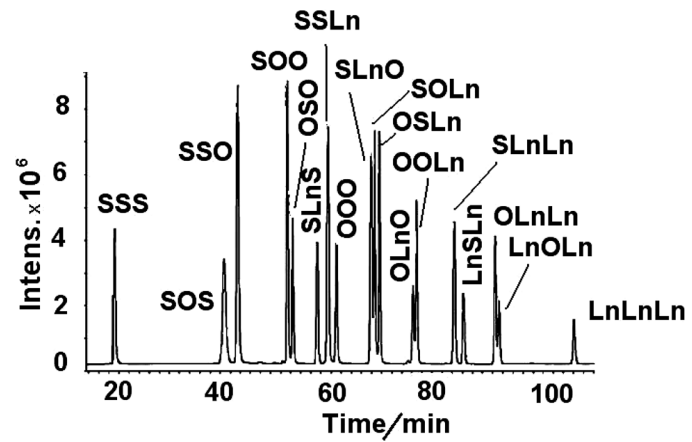

Fig. 10 Separation of a test mixture of randomized SSS, OOO and LnLnLn triacylglycerols (S, stearic; O, oleic; Ln, linolenic acid moieties) by Ag-HPLC-APCI-MS. ${ }^{20}$ Three CSL columns connected in series; linear gradient of $100 \%$ hexane:2-propanol:acetonitrile, 99.8:0.1:0.1 (v/v/v) to $61 \%$ hexane:2-propanol:acetonitrile, 99.8:0.1:0.1 - 39\% hexane:2-propanol:acetonitrile, 96:2:2 (v/v/v) over $140 \mathrm{~min}$ at a flow rate of $1 \mathrm{~mL} / \mathrm{min}$; sample size, $20 \mu \mathrm{g}$ (redrawn from the original with permission of Elsevier).

columns. In fine recent work, a complementary off-line combination of Ag-HPLC-ELSD, RP-HPLC-ELSD, GC, MS and MS/MS was applied to not only fractionate TAG, depending on the configuration of double bond in monoenoic FA moieties (milk fat), but also to determine the location of the moieties between the primary and secondary positions of TAG. ${ }^{84}$ Using three CSL columns in series, it was possible to separate a standard mixture of a randomized OOO/EEE mixture (O, oleic; E, elaidic acid moieties) into species differing by the number of elaidic acid moieties in the TAG (which is not a novelty), while achieving a partial separation of the pairs EEO/EOE and OOE/OEO in the same single run. ${ }^{28}$ TAG species differing in the position of double bonds in a single acyl moiety, $\alpha$ - and $\gamma$-linolenoyl ( $\mathrm{Ln})$, were successfully resolved, including the pairs $\mathrm{OO} \alpha \operatorname{Ln} / \mathrm{OO} \gamma \operatorname{Ln}$ and $\gamma \operatorname{Ln} \gamma \operatorname{Ln} \gamma \operatorname{Ln} / \alpha \operatorname{Ln} \alpha \operatorname{Ln} \alpha \operatorname{Ln}\left(\right.$ Fig. 8). ${ }^{20}$ An attempt to separate species of TAG containing CLA by using four CSL columns connected in series resulted in partial resolution and ambiguous detection. ${ }^{19}$ The separation of EEE/OOO on the new silver thiolate chromatographic material $(\mathrm{AgTCM})^{22}$ is presented in Fig. 9.

\subsection{Separation of regioisomeric TAG}

The use of silver ion chromatography is considered to be a necessity in this separation, which is of significant practical importance. The efficient separation of $\mathrm{S}_{2} \mathrm{U}$ type TAG 
Table 1 Some applications of Ag-HPLC for analysis of fatty acids ${ }^{\mathrm{a}}$ and triacylglycerols $(2001-2011)$

\begin{tabular}{|c|c|c|c|c|}
\hline Analyte & $\begin{array}{c}\text { Column }^{\mathrm{b}} \\
\text { (temperature) }\end{array}$ & $\begin{array}{l}\text { Mobile phase }^{\mathrm{b}} \\
\text { (flow rate) }\end{array}$ & $\begin{array}{c}\text { Detection }^{\mathrm{b}} \\
\text { (sample size) }\end{array}$ & Ref. \\
\hline $\begin{array}{l}\text { trans/cis isomers of } 20: 5 \\
\text { and } 22: 6\end{array}$ & $\mathrm{CSL}^{\mathrm{c}}$ column & $0.3 \%$ Acetonitrile in hexane & UV $(0.08 \mathrm{mg})$ & 55 \\
\hline $\begin{array}{l}\text { trans/cis } 18: 1 \text { positional } \\
\text { isomers }\end{array}$ & CSL column & $\begin{array}{l}0.018 \% \text { Acetonitrile }+0.18 \% \text { 2-propanol in hexane } \\
(0.2 \mathrm{~mL} / \mathrm{min})\end{array}$ & $\begin{array}{l}\text { APPI-MS } \\
(54 \mathrm{ng})\end{array}$ & 33 \\
\hline $\begin{array}{l}\text { trans/cis } 17: 1 \text { positional } \\
\text { isomers }\end{array}$ & $\begin{array}{l}3 \text { connected CSL } \\
\text { columns }\end{array}$ & $0.15 \%$ Acetonitrile in 2 -octane $(1 \mathrm{~mL} / \mathrm{min})$ & $\mathrm{UV}$ at $200 \mathrm{~nm}$ & 35 \\
\hline $\begin{array}{l}\text { trans/cis } 18: 1 \text { positional } \\
\text { isomers as } p \text {-methoxy- } \\
\text { phenacyl esters }\end{array}$ & $\begin{array}{l}\text { Nucleosil }{ }^{\mathrm{TM}} 100-5 \mathrm{SA} \\
\text { column with } \mathrm{Ag}^{+}\left(21^{\circ} \mathrm{C}\right)\end{array}$ & $\begin{array}{l}\text { Hexane:dichloromethane:acetonitrile, } \\
\text { 60:40:0.2 }(1 \mathrm{~mL} / \mathrm{min})\end{array}$ & $\begin{array}{l}\mathrm{UV} \text { at } 270 \mathrm{~nm} \\
(20 \mu \mathrm{g})\end{array}$ & 62 \\
\hline $\begin{array}{l}\text { Saturated, 6-, 9-, } 11- \\
18: 1,18: 2,18: 3 \text { in plant } \\
\text { oils as } p \text {-methoxy- } \\
\text { phenacyl esters }\end{array}$ & $\begin{array}{l}\text { Nucleosil }^{\mathrm{TM}} 100-5 \mathrm{SA} \\
\text { column with } \mathrm{Ag}^{+}\left(21^{\circ} \mathrm{C}\right)\end{array}$ & $\begin{array}{l}\text { Gradient of: A) dichloromethane; B) dichloromethane: } \\
\text { acetonitrile, } 99: 1 \text {; C) dichloromethane:acetonitrile, } 97: 3 \\
(1 \mathrm{~mL} / \mathrm{min})\end{array}$ & $\begin{array}{l}\mathrm{UV} \text { at } 280 \mathrm{~nm} \\
(5-7 \mu \mathrm{g})\end{array}$ & 63 \\
\hline $\begin{array}{l}\text { CLA }{ }^{\mathrm{d}} \text { standard mixture, } \\
\text { CLA metabolites }\end{array}$ & $\begin{array}{l}2 \text { - } 3 \text { connected CSL } \\
\text { columns }\left(30^{\circ} \mathrm{C}\right)\end{array}$ & $0.2 \%$ Propionitrile in hexane $(0.6-1 \mathrm{~mL} / \mathrm{min})$ & $\begin{array}{l}\text { APPI-MS } \\
(4 \mu \mathrm{g})\end{array}$ & 36,37 \\
\hline CLA standard mixture & $\begin{array}{l}3 \text { connected CSL } \\
\text { columns }\left(30^{\circ} \mathrm{C}\right)\end{array}$ & $\begin{array}{l}0.1 \% \text { Acetonitrile }+0.5 \% \text { diethyl ether in hexane or } 2 \% \\
\text { acetic acid in hexane }(1 \mathrm{~mL} / \mathrm{min})\end{array}$ & $\mathrm{UV}$ at $233 \mathrm{~nm}$ & 30,34 \\
\hline CLA standard mixture & $\begin{array}{r}3 \text { connected CSL } \\
\text { columns }\left(21^{\circ} \mathrm{C}\right)\end{array}$ & $\begin{array}{l}0.1 \% \text { Acetonitrile }+0.5 \% \text { diethyl ether }+0.05 \% \\
\text { 2-propanol in hexane }(1 \mathrm{~mL} / \mathrm{min})\end{array}$ & $\begin{array}{l}\mathrm{UV} \text { at } 233 \mathrm{~nm} \\
(1.5 \mu \mathrm{g})\end{array}$ & 32 \\
\hline CLA in food products & 1 - 4 CSL columns & $0.1 \%$ Acetonitrile in hexane $(1 \mathrm{~mL} / \mathrm{min})$ & $\mathrm{UV}$ at $233 \mathrm{~nm}$ & $68-80$ \\
\hline $\begin{array}{l}\text { CLnA } \mathrm{A}^{\mathrm{e}} \text { standard mixture } \\
\text { of } 2 \text { isomers }\end{array}$ & $\mathrm{CSL}$ column $\left(30^{\circ} \mathrm{C}\right)$ & $87 \%$ Hexane $+13 \%$ hexane:acetonitrile, $100: 2(1 \mathrm{~mL} / \mathrm{min})$ & $\mathrm{UV}$ at $230 \mathrm{~nm}$ & 81 \\
\hline TAG of butterfat & $\begin{array}{l}\text { Nucleosil }{ }^{\mathrm{TM}} 100-5 \mathrm{SA} \\
\text { column with } \mathrm{Ag}^{+}\end{array}$ & $\begin{array}{l}\text { Gradient of: A) dichloroethane:dichloromethane, } 4: 1 \text {; } \\
\text { B) acetone }(1 \mathrm{~mL} / \mathrm{min})\end{array}$ & $\begin{array}{l}\text { ELSD } \\
(1-2.5 \mathrm{mg})\end{array}$ & 84 \\
\hline TAG of vegetable oils & $\begin{array}{l}\text { silver modified column } \\
150 \mathrm{~mm} \times 1 \mathrm{~mm} \\
\text { (Varian, Palo Alto, USA) }\end{array}$ & $0.5-1.5 \%$ Butyronitrile in hexane $(0.013 \mathrm{~mL} / \mathrm{min})$ & ELSD (6 mg) & 38 \\
\hline $\begin{array}{l}\text { Standard mixture of } \\
\text { TAG containing CLA }\end{array}$ & $\begin{array}{l}3 \text { - } 4 \text { connected CSL } \\
\text { columns }\end{array}$ & $0.6-1 \%$ Acetonitrile in hexane $(1.5-2 \mathrm{~mL} / \mathrm{min})$ & $\begin{array}{r}\mathrm{UV} \text { at } 206 \mathrm{~nm} \\
(50-100 \mu \mathrm{g})\end{array}$ & 19 \\
\hline $\begin{array}{l}\text { Isomeric TAG standard } \\
\text { mixtures, TAG of } \\
\text { animal fats }\end{array}$ & $\begin{array}{r}3 \text { connected CSL } \\
\text { columns }\left(25^{\circ} \mathrm{C}\right)\end{array}$ & $\begin{array}{l}\text { Gradient of: A) hexane:2-propanol:acetonitrile, } \\
\text { 99.8:0.1:0.1; B) hexane:2-propanol:acetonitrile, 96:2:2 } \\
(1 \mathrm{~mL} / \mathrm{min})\end{array}$ & APCI-MS & 20,44 \\
\hline $\begin{array}{l}\text { trans/cis TAG positional } \\
\text { isomers in partially } \\
\text { hydrogenated oils }\end{array}$ & CSL column $\left(22-25^{\circ} \mathrm{C}\right)$ & $\begin{array}{l}\text { Gradient of: A) heptane:acetonitrile, 100:0.1; B) heptane: } \\
\text { acetonitrile, 100:1 (1 mL/min) }\end{array}$ & $\begin{array}{l}\text { ELSD } \\
(250-350 \mu \mathrm{g})\end{array}$ & 39 \\
\hline $\begin{array}{l}\text { TAG positional isomers } \\
\text { in rice oil }\end{array}$ & CSL column $\left(34^{\circ} \mathrm{C}\right)$ & $0.5 \%$ Acetonitrile in hexane $(1 \mathrm{~mL} / \mathrm{min})$ & APCI-MS & 27 \\
\hline
\end{tabular}

a. Fatty acids were analyzed as methyl esters unless other was specified. b. Additional information is missing in the original. c. ChromSpherLipids ${ }^{\mathrm{TM}}$ column by Varian-Chrompack International (Middelburg, Netherlands). d. Conjugated linoleic acid (trans/cis positional 18:2 isomers with conjugated double bonds). e. Conjugated linolenic acid (trans/cis positional 18:3 isomers with conjugated double bonds).

(S, saturated acyl moiety; U, unsaturated acyl moiety) by Ag-HPLC is indeed unbeatable in meeting the needs of the analysis of structured TAG.

Now, efforts are being directed to the resolution and identification of regioisomeric TAG of higher unsaturation in natural samples, and should be considered as the first serious steps in employing silver ion chromatography as a necessary stage in lipidomics. Natural samples usually contain large amounts of $\mathrm{SU}_{2}$ or $\mathrm{U}_{3} \mathrm{TAG}$, and their regioisomeric composition is in general unknown. For example, RP- (on two columns) and Ag-HPLC-APCI (on three columns, see Fig. 10) as first and second stages were combined to determine a remarkable number of isomeric TAG in reference samples, blackcurrant oil and beef tallow. ${ }^{28}$

In a perspective approach, regioisomeric and enantiomeric $\mathrm{S}_{2} \mathrm{U}$ type TAG were separated and identified by using Ag-HPLC and HPLC on chiral column in a complementary way. ${ }^{85}$ The use of chiral chromatography for the separation of enantiomeric TAG isomers should be seriously accounted in the future as an important stage in lipidomics. ${ }^{86}$
Some typical applications of Ag-HPLC for the analysis of FA and TAG during the last decade are summarized in Table 1.

\section{Conclusions}

There is a clear tendency at present to accept that the best approach to enlighten the composition of natural lipids is to combine all chromatographic, spectral and chemical techniques available, as has been recommended for years by leading lipid chemists. The coupling of Ag-HPLC with either ESI-MS or APCI-MS detectors is undoubtedly highly efficient, and is gaining increasing popularity. We believe that silver ion chromatography will be a useful and unavoidable stage in lipid analysis, and has strong prospective for applications in lipidomics, especially when combining with RP- and chiral HPLC and MS detection. 


\section{Acknowledgements}

Partial financial support of the Bulgarian National Science Fund, contract DO02-239, is gratefully acknowledged.

\section{References}

1. L. J. Morris, J. Lipid Res., 1966, 7, 717.

2. "Advances in Lipid Methodology-One", ed. W. W. Christie, 1992, The Oily Press, Ayr, Scotland.

3. "Advances of Lipid Methodology-Five", ed. R. O. Adlof, 2003, The Oily Press, Bridgwater, England.

4. "Lipid Analysis", ed. W. W. Christie and X. Han, 4th ed., 2010, The Oily Press, Bridgwater, England.

5. P. Kairenius, V. Toivonen, and K. J. Shingfield, Lipids, 2011, 46, 587.

6. M. Y. Pasquevich, M. S. Dreon, S. Lavarias, and H. Heras, Comp. Biochem. Physiol., Part B: Biochem. Mol. Biol., 2011, 160, 201.

7. Sv. Momchilova and B. Nikolova-Damyanova, J. Sep. Sci., 2003, 26, 261.

8. Sv. Momchilova and B. Nikolova-Damyanova, in "ThinLayer Chromatography in Phytochemistry", ed. M. Waksmundzka-Hajnos, J. Sherma, and T. Kowalska, 2008, CRC Press, Taylor \& Francis Group, Boca Raton, London, New York, 277.

9. M. Buchgraber, F. Ulberth, H. Emons, and E. Anklam, Eur. J. Lipid Sci. Technol., 2004, 106, 621.

10. B. Fuchs, R. Süß, K. Teuber, M. Eibisch, and J. Schiller, J. Chromatogr., A, 2011, 1218, 2754.

11. W. W. Christie, J. Lipid Res., 1989, 30, 1471.

12. M. Li, P. J. Pham, T. Wang, C. U. Pittman, and T. Y. Li, Bioresour. Technol., 2009, 100, 6385.

13. S. Hauff, L. Rilfors, G. Hottinger, and W. Vetter, J. Chromatogr., A, 2010, 1217, 1683.

14. J. Dreiucker and W. Vetter, Food Chem., 2011, 126, 762.

15. B. Nikolova-Damyanova, in "Lipid Methodology-One", ed. W. W. Christie, 1992, The Oily Press, Ayr, Scotland, 181.

16. B. Nikolova-Damyanova, in "Advances of Lipid Methodology-Five", ed. R. O. Adlof, 2003, The Oily Press, Bridgwater, England, 43.

17. W. W. Christie, J. High Resolut. Chromatogr., Chromatogr. Commun., 1987, 10, 148.

18. W. W. Christie, G. Dobson, and R. O. Adlof, Lipids, 2007, 42, 1073.

19. R. O. Adlof, A. Menzel, and V. Dorovska-Taran, J. Chromatogr., A, 2002, 953, 293.

20. M. Holcapek, H. Dvorakova, M. Lisa, A. J. Giron, P. Sandra, and J. Cvacka, J. Chromatogr., A, 2010, 1217, 8186.

21. J. C. Aponte, J. T. Dillon, R. Tarozo, and Y. Huang, J. Chromatogr., A, 2012, 1240, 83.

22. J. T. Dillon, J. C. Aponte, R. Tarozo, and Y. Huang, J. Chromatogr., A, 2012, 1240, 90.

23. B. Nikolova-Damyanova, J. Chromatogr., A, 2009, 1216, 1815.

24. P. Dugo, T. Kumm, M. L. Crupi, A. Cotroneo, and L. Mondello, J. Chromatogr., A, 2006, 1112, 269.

25. P. Dugo, T. Kumm, B. Chiofalo, A. Cotroneo, and L. Mondello, J. Sep. Sci., 2006, 29, 1146.

26. L. Mondello, P. Q. Tranchida, V. Stanek, P. Jandera, G. Dugo, and P. Dugo, J. Chromatogr., A, 2005, 1086, 91.
27. P. Dugo, O. Favoino, P. Q. Tranchida, G. Dugo, and L. Mondello, J. Chromatogr., A, 2004, 1041, 135.

28. M. Holcapek, H. Velinska, M. Lisa, and P. Cesla, J. Sep. Sci., 2009, 32, 3672.

29. W. E. Neff, R. O. Adlof, and M. El-Agaimy, J. Am. Oil Chem. Soc., 1994, 71, 853.

30. P. Delmonte, M. P. Yurawecz, M. M. Mossoba, C. Cruz-Hernandez, and J. K. G. Kramer, J. AOAC Int., 2004 , 87, 563.

31. M. A. de la Fuente, P. Luna, and M. Juarez, Trends Anal. Chem., 2006, 25, 917.

32. K. Kuhnt, C. Degen, and G. Jahreis, J. Chromatogr., B, 2010, 878,88

33. C. Villegas, Y. Zhao, and J. M. Curtis, J. Chromatogr., A, 2010, 1217,775 .

34. P. Delmonte, A. Kataoka, B. A. Corl, D. E. Bauman, and M. P. Yurawecz, Lipids, 2005, 40, 509.

35. P. Delmonte, Q. Hu, A.-R. F. Kia, and J. I. Rader, J. Chromatogr., A, 2008, 1214, 30.

36. A. Muller, K. Dusterloh, R. Ringseis, K. Eder, and H. Steinhart, J. Sep. Sci., 2006, 29, 358.

37. A. Muller, M. Mickel, R. Geyer, R. Ringseis, K. Eder, and H. Steinhart, J. Chromatogr., B, 2006, 837, 147.

38. R. G. Harfmann, S. Julka, and H. J. Cortes, J. Sep. Sci., 2008, 31, 915 .

39. M.-B. Macher and A. Holmqvist, J. Sep. Sci., 2001, 24, 179.

40. R. Adlof and G. List, J. Chromatogr., A, 2004, 1046, 109.

41. R. Adlof, J. Chromatogr., A, 2007, 1148, 256.

42. W. C. Byrdwell, in "Advances of Lipid MethodologyFive", ed. R. O. Adlof, 2003, The Oily Press, Bridgwater, England, 171.

43. W. C. Byrdwell, "Modern Methods for Lipid Analysis by Liquid Chromatography/Mass Spectrometry and Related Techniques", 2005, AOCS Press, Champaign, IL.

44. M. Lisa, K. Netusilova, L. Franek, H. Dvorakova, V. Vrkoslav, and M. Holcapek, J. Chromatogr., A, 2011, 1218 , 7499.

45. D. Bicanic, G. Mocnik, M. Franko, H. A. G. Niederlander, P. van de Bovenkamp, and J. Cozijnsen, Instrum. Sci. Technol., 2006, 34, 129.

46. F. A. Kummerow, M. M. Mahfouz, and Q. Zhou, Prostaglandins Other Lipid Mediators, 2007, 84, 138.

47. M. G. Sajilata, R. S. Singhal, and M. Y. Kamat, Food Chem., 2008, 109, 580.

48. L. Kleiner-Shuhler, L. Vazquez, and C. C. Akoh, J. Am. Oil Chem. Soc., 2011, 88, 1161.

49. I. Marekov, R. Tarandjiiska, S. Panayotova, and N Nikolova, J. Planar Chromatogr., 2001, 14, 384.

50. I. Marekov, R. Tarandjiiska, S. Panayotova, and N. Nikolova, Eur. J. Lipid Sci. Technol., 2002, 104, 410.

51. I. Marekov, D. Nedelcheva, S. Panayotova, and R. Tarandjiiska, J. Liq. Chromatogr. Relat. Technol., 2011, 34, 888.

52. C. Cruz-Hernandez, Z. Deng, J. Zhou, A. R. Hill, M. P. Yurawecz, P. Delmonte, M. M. Mossoba, M. E. R. Dugan, and J. K. G. Kramer, J. AOAC Int., 2004, 87, 545.

53. J. K. G. Kramer, C. Cruz-Hernandez, Z. Deng, J. Zhou, G. Jahreis, and M. E. R. Dugan, Am. J. Clin. Nutr., 2004, 79(suppl.), 1137S.

54. P. Juaneda, M. Ledoux, and J.-L. Sebedio, Eur. J. Lipid Sci. Technol., 2007, 109, 901.

55. V. Fournier, P. Juaneda, F. Destaillats, F. Dionisi, P. Lambelet, J.-L. Sebedio, and O. Berdeaux, J. Chromatogr., A, 2006, 1129, 21. 
56. M. Buchgraber and F. Ulberth, J. AOAC Int., 2001, 84, 1490.

57. I. Marekov, S. Panayotova, and R. Tarandjiiska, J. Liq. Chromatogr. Relat. Technol., 2009, 32, 1183.

58. M. P. Mansour, D. G. Holdsworth, S. E. Forbes, C. K. Macleod, and J. K. Volkman, Bioch. Syst. Ecol., 2005, 33, 659.

59. D. Nikolova, D. Antonova, I. Marekov, and B. NikolovaDamyanova, Eur. J. Lipid Sci. Technol., 2006, 108, 212.

60. B. Nikolova-Damyanova and S. Momchilova, J. Liq. Chromatogr. Relat. Technol., 2002, 25, 1947.

61. B. Nikolova-Damyanova, in "HPLC of Acyl Lipids", ed. T. A. McKeon and J.-T. Lin, 2005, HNB Publishing, New York, 221.

62. S. M. Momchilova and B. M. Nikolova-Damyanova, Nat. Protoc., 2010, 5, 473.

63. R. V. Denev, I. S. Kuzmanova, S. M. Momchilova, and B M. Nikolova-Damyanova, J. AOAC Int., 2011, 94, 4.

64. M. P. Yurawecz and K. M. Morehouse, Eur. J. Lipid Sci. Technol., 2001, 103, 609.

65. J. A. G. Roach, M. M. Mossoba, M. P. Yurawecz, and J. K. G. Kramer, Anal. Chim. Acta, 2002, 465, 207.

66. "Advances in Conjugated Linoleic Acid Research", ed. J.-L. Sebedio, W. W. Christie, and R. Adlof, 2003, Vol. 2, AOCS Press, Champaign, IL.

67. "Advances in Conjugated Linoleic Acid Research", ed. M. P. Yurawecz, J. K. G. Kramer, O. Gudmundsen, M. W. Pariza, and S. Banni, 2006, Vol. 3, AOCS Press, Champaign, IL.

68. L. M. Rodriguez-Alcala and J. Fontecha, J. Dairy Sci., 2007, 90, 2083.

69. S. V. Martins, P. A. Lopes, C. M. Alfaia, V. S. Ribeiro, T. V. Guerreiro, C. M. G. A. Fontes, M. F. Castro, G. Soveral, and J. A. M. Prates, Br. J. Nutr., 2007, 98, 1206.

70. J. C. Nunes and A. G. Torres, J. Food Comp. Anal., 2010,
23, 782 .

71. S. Mushtaq, M. E. Heather, and K. A. Hunter, Br. J. Nutr., 2010, 103, 1366.

72. P. Luna, A. Bach, M. Juarez, and M. A. De La Fuente, $J$. Dairy Sci., 2008, 91, 20.

73. P. Gomez-Cortes, P. Frutos, A. R. Mantecon, M. Juarez, M. A. De La Fuente, and G. Hervas, J. Dairy Sci., 2008, 91, 3119.

74. J. L. Rodriguez-Castanedas, M. J. Pena-Egido, M. Garcia-Marino, and C. Garcia-Moreno, J. Food Comp. Anal., 2011, 24, 1004

75. K. Nuernberg, D. Dannenberger, K. Ender, and G. Nuernberg, J. Agric. Food Chem., 2007, 55, 598.

76. P. G. Toral, K. J. Shingfield, G. Hervas, V. Toivonen, and P. Frutos, J. Dairy Sci., 2010, 93, 4804.

77. O. A. Rego, S. P. Alves, L. M. S. Antunes, H. J. D. Rosa, C. F. M. Alfaia, J. A. M. Prates, A. R. J. Cabrita, A. J. M Fonseca, and R. J. B. Bessa, J. Dairy Sci., 2009, 92, 4530.

78. X. Shen, D. Dannenberger, K. Nuernberg, G. Nuernberg, and R. Zhao, Lipids, 2011, 46, 831.

79. P. Luna, M. Juarez, and M. A. De La Fuente, Eur. J. Lipid Sci. Technol., 2007, 109, 1160.

80. L. M. Rodriguez-Alcala, T. Braga, F. Xavier Malcata, A. Gomes, and J. Fontecha, Food Chem., 2011, 125, 1373.

81. M. Plourde, F. Destaillats, P. Y. Chouinard, and P. Angers, J. Dairy Sci., 2007, 90, 5269.

82. J. Cvacka, O. Hovorka, P. Jiros, J. Kindl, K. Stransky, and I. Valterova, J. Chromatogr., A, 2006, 1101, 226.

83. P. Sandra, A. Medvedovici, Y. Zhao, and F. David, J. Chromatogr., A, 2002, 974, 231.

84. H. Kallio, K. Korkiasaari, O. Sjovall, J.-P. Suomela, and K. Linderborg, J. Am. Oil Chem. Soc., 2006, 83, 407.

85. Y. Iwasaki, M. Yasui, T. Ishikawa, R. Irimescu, K. Hata, and T. Yamane, J. Chromatogr., A, 2001, 905, 111.

86. A. Kuksis and Y. Itabashi, Methods, 2005, 36, 172. 